\title{
Optimization of mechanical properties of non-woven short sisal fibre-reinforced vinyl ester composite using factorial design and GA method
}

\author{
S VELUMANI*，P NAVANEETHAKRISHNAN ${ }^{\dagger}$, S JAYABAL ${ }^{\dagger \dagger}$ and D S ROBINSON SMART ${ }^{\#}$ \\ Department of Mechanical Engineering, Velalar College of Engineering and Technology, Erode 638 012, India \\ $\dagger^{\dagger}$ Department of Mechanical Engineering, Kongu Engineering College, Perundurai 638 052, India \\ ${ }^{\dagger}$ Department of Mechanical Engineering, A.C. College of Engineering and Technology, Karaikudi 630 004, India \\ \#Department of Mechanical Engineering, Karunya University, Coimbatore 641 114, India
}

MS received 11 May 2011; revised 24 May 2012

\begin{abstract}
This work presents a systematic approach to evaluate and study the effect of process parameters on tensile, flexural and impact strength of untreated short sisal fibre-reinforced vinyl ester polymer-based composites and predicts the optimum properties of random natural fibre-reinforced composites. The natural fibre of sisal at lengths of 10, 30 and $50 \mathrm{~mm}$ and vinyl ester resin at loadings of 15, 30 and 45 (wt \%) were prepared. The composite panel was then fabricated using hand lay method in cold process of size $180 \times 160 \mathrm{~mm}^{2}$. Samples were then cut from the panel and subjected to mechanical properties testing such as tensile, flexural and impact strengths. The average tensile strength ranges between 27.1 and 43.9 MPa. The flexural strength ranged between 26.9 and 49.5 MPa and the impact strength ranged between 16 and $93 \mathrm{~J} / \mathrm{m}$. The strength values were optimized using factorial design and genetic algorithm (GA) method. The predicted optimum process parameter values are in good agreement with the experimental results.
\end{abstract}

Keywords. Sisal fibre; composites; polymer matrix; mechanical properties.

\section{Introduction}

In the field of composites, the fibre-reinforced matrices were initially developed using man-made fibres such as carbon, aramid, glass, etc, due to the advantage of their high tensile modulus (Joly et al 1996). But in the recent past, a good deal of work has been dedicated to natural fibres with the aim of replacing man-made fibres (Woodhams et al 1984). There are many reasons to select these natural fibres as reinforcement. They have easy renewability, availability throughout the world and good biodegradability. Relating to the basic properties, these fibres have a specific weight far less than glass and also their tensile modulus is higher than that of the aramid fibres (Sotton and Ferrari 1989; Joseph et al 1999). In recent years, polymer composites reinforced with short natural fibres have gained wide importance because of the advantages they impart in processing and their low cost coupled with high strength (Cruz-Ramos and Carlos 1986).

Although sisal fibre is one of the most extensively used natural fibres, a large quantity of this economic and renewable resource is still not fully utilized. Now, sisal fibre is mainly used as ropes in the marine and agricultural industries. Other applications of sisal fibres include twines, cords, upholstery, padding, mat making, fishing nets and fancy

\footnotetext{
*Author for correspondence (velumani2003@gmail.com)
}

articles such as purses, wall hangings, table mats, etc. The use of sisal fibre as a reinforcement in composites has raised great interest and expectations among the material scientists and engineers (Zhang and Horrocks 2003). Among the various natural fibres, sisal fibres possess moderately high specific strength and stiffness and hence, can be used as a reinforcing material in polymeric resin matrices to make useful structural composite materials (Pavithran et al 1987). Sisal fibre is extracted from the plant Agave sisalana and is available in abundant quantity in southern parts of India, north and south America, Africa and West Indies. The incorporation of sisal fibres into plastics and elastomers to obtain cost reduction and reinforcements have been reported by various researchers.

Sisal fibre-reinforced urea formaldehyde matrix composite was investigated for impact strength, flexural strength and wear resistance (Zhong et al 2007). There has been enhancement in the tensile and flexural properties with increase in the carbon fibre content in the unsaturated vinyl ester-based sisal/carbon fibre reinforced hybrid composites (Noorunnisa Khanam et al 2010). With minimum number of experiments, process variables can be effectively optimized using RSM method (Yadav et al 2007). The higher value of mechanical properties were obtained by developing a model using regression analysis and the higher value of mechanical properties were found, when coir fibre length was at its maximum length (Jayabal et al 2011). 
In the present work, untreated sisal composite has been prepared using chopped fibre lengths of 10, 30 and $50 \mathrm{~mm}$ and fibre contents 15, 30 and 45. Unsaturated vinyl ester resin was used as matrix for preparing the composites with different combinations of fibre length and fibre content (wt $\%$ ). The composite sheets were produced as single layer composite. Mathematical modeling was developed. Mechanical properties such as tensile, flexural and impact strength were studied for these sisal composites. The response variables were optimized by factorial design and genetic algorithm technique.

\section{Experimental}

\subsection{Material}

In the composite production, thermosetting resin mixture and a fibre were used. It was a cold-setting laminating resin system consisting of vinyl ester resin, MEKP catalyst, cobalt naphthenate promoter $(6 \%)$ and dimethyl aniline accelerator. All these items were supplied by $\mathrm{M} / \mathrm{s}$ Covai Seenu and company, Coimbatore. Sisal fibres used in this study were received from APK Industries, Erode. The sisal fibres were of good quality and their diameters varied substantially in the range $0 \cdot 080-0 \cdot 250 \mathrm{~mm}$.

\subsection{Composite fabrication}

To prepare the composite, vinyl ester resin was used as the matrix material. The chopped sisal fibre composite sheets were manufactured by simple hand lay-up process in a mould at laboratory temperature (cold process). For easier removal of the composite panel from the mould, the frame and the board were treated with a parting compound, i.e. poly vinyl acetate. Releasing agent was applied to the surfaces before moulding. Chopped non-woven sisal fibres were pre-impregnated with the matrix material consisting of vinyl ester resin, accelerator, catalyst and promoter in the ratio

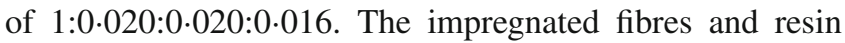
were poured in the mould frame of size $180 \times 160 \mathrm{~mm}^{2}$. Nine composite laminates with different combinations of fibre length (10, 30 and $50 \mathrm{~mm})$ and fibre content $(15,30$ and $45 \mathrm{wt} \%$ ) were designed and produced. The pouring was continued till the thickness reached $3 \mathrm{~mm}$ and then pressed heavily for $3 \mathrm{~h}$ before removal. Then, the composite sheet was removed from the mould and cured at room temperature for $24 \mathrm{~h}$. After the curing process, test samples were cut according to the sizes of ASTM standards.

\section{Mechanical tests}

\subsection{Characteristics of composites}

The composites were investigated for their tensile, flexural and impact properties for the pre-fixed fibre length and fibre content of produced composite laminates. The pure resin sample without fibre reinforcement acted as reference for the experiments. Before going for testing, the samples were conditioned for at least $24 \mathrm{~h}$ at $23{ }^{\circ} \mathrm{C}$ and $50 \%$ relative humidity.

3.1a Tensile strength test: The tensile strength properties were determined according to ASTM 638-08. The length, width and thickness of each sample were $\sim 165,25$ and $3 \mathrm{~mm}$. For this testing, the composite sheets were cut into number of specimens. The tensile specimens were tested in a Tenso meter tensile testing machine (Kudale Instruments (P) Ltd., India) with a preload of $50 \mathrm{~N}$ and having a displacement speed of $2 \mathrm{~mm} / \mathrm{min}$. The gauge length was $135 \mathrm{~mm}$. Five specimens were tested for each combination of fibre parameters. The calculated results were the average values of sample responses from the five specimens. The tested mechanical property values for the nine combinations of fibre parameters are shown in table 1 . The tensile strength of all the nine combinations are shown in figure 1.

Table 1. Mechanical properties of composite sheets.

\begin{tabular}{llllll}
\hline Identification & $f_{1}$ & $f_{2}$ & $t s$ & $f_{s}$ & is \\
\hline A1 & 10 & 15 & $27 \cdot 1$ & $26 \cdot 9$ & 16 \\
A2 & 30 & 15 & $37 \cdot 7$ & $41 \cdot 1$ & 64 \\
A3 & 50 & 15 & $42 \cdot 8$ & $47 \cdot 5$ & 89 \\
A4 & 10 & 30 & $31 \cdot 0$ & $33 \cdot 1$ & $34 \cdot 7$ \\
A5 & 30 & 30 & $41 \cdot 0$ & $44 \cdot 5$ & 75 \\
A6 & 50 & 30 & $45 \cdot 1$ & $49 \cdot 5$ & $91 \cdot 7$ \\
A7 & 10 & 45 & $34 \cdot 5$ & $38 \cdot 7$ & $47 \cdot 5$ \\
A8 & 30 & 45 & $42 \cdot 0$ & $46 \cdot 3$ & 85 \\
A9 & 50 & 45 & $43 \cdot 9$ & $47 \cdot 8$ & 93 \\
\hline
\end{tabular}

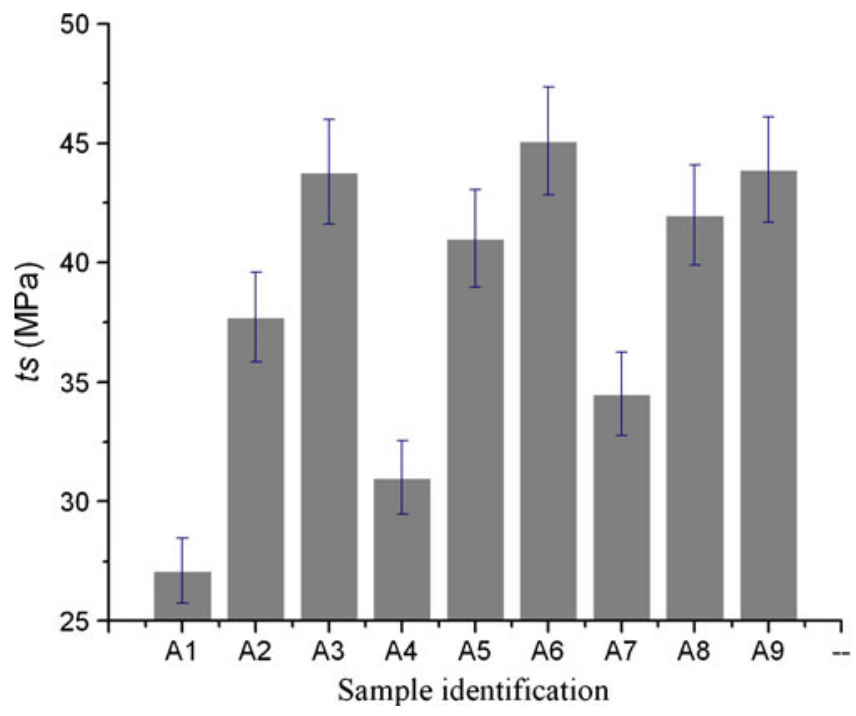

Figure 1. Effect of fibre parameters on tensile strength. 
3.1b Flexural strength test: The rectangular test pieces of $127 \times 12.7 \times 3 \mathrm{~mm}^{3}$ dimensions for flexural test were cut from the prepared randomly oriented fibre composites. Flexural test was conducted as per ASTM D790. The test was conducted on the spring testing machine. The specimen was freely supported by a beam and the load was applied in the middle of the specimen. The tests were carried out at a temperature of $27{ }^{\circ} \mathrm{C}$ and at a relative humidity of $50 \%$. For statistical purposes, a total of five samples were tested for each run and quoted in table 1. Comparisons of flexural strength properties of different combinations are shown in figure 2.

3.1c Impact strength test: For the Izod impact strength test, rectangular unnotched specimens $\left(80 \times 10 \times 3 \mathrm{~mm}^{3}\right)$ were cut from the produced laminate sheet and tested according to ASTM D 256 standards. Impact strength was measured

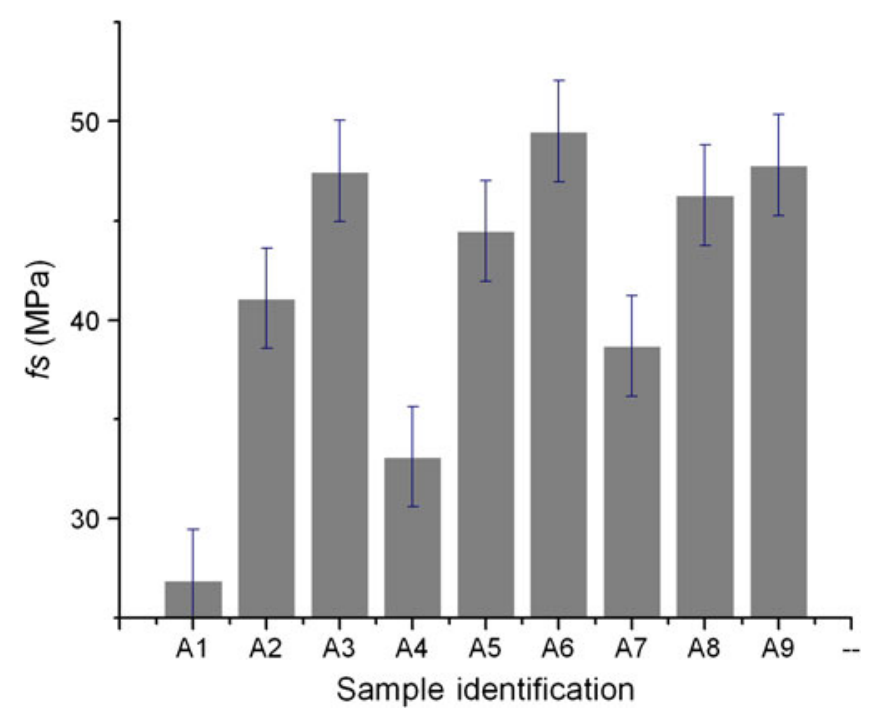

Figure 2. Effect of fibre parameters on flexural strength.

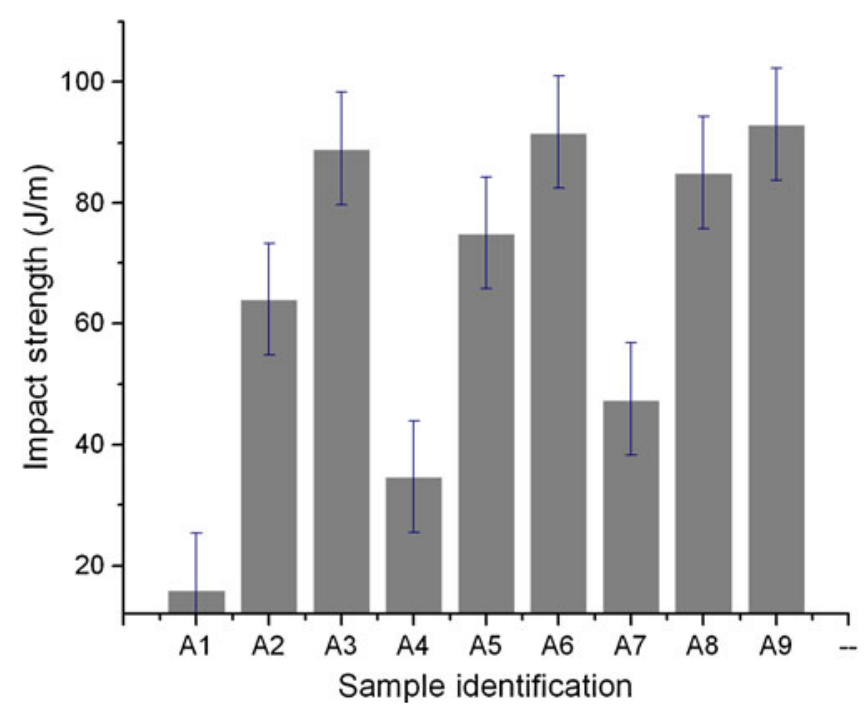

Figure 3. Effect of fibre parameters on impact strength. on Geeth Impact testing machine, India and the machine capacity is $20 \mathrm{~J}$. For each testing procedure, five specimens were tested. All the results shown in table 1 under the column of impact strength are taken as the average reading of the five measured samples from each run. The impact strength values attained are displayed in figure 3.

\section{Factorial design method}

Factorial designs were used first by John Bennet Lawes and Joseph Henry Gilbert of Rothamsted Experimental Station in 19th century. Factorial design is a systematic method that investigates the effects of two or more factors on the output response process. Each complete trial or replication of the experiment takes into account all the possible combinations of the varying levels of these factors. Effective factorial design ensures that the least number of experiment runs are conducted to generate the maximum amount of information about how input variables affect the output of a process.

In this case, two factors (fibre length and fibre content) are the parameters with three levels $(-1,0,1)$ in each factor (fibre length of 10, 30 and $50 \mathrm{~mm}$ and fibre content of 15, 30 and $45 \%$ ), so totally $3 \times 3=9$ runs (experiments) were conducted for studying the influence on the response of tensile, flexural and impact strengths.

The main effect of a factor is essentially the 'average' change in the output response as that factor goes from 'to ' + '. Mathematically, this is the average of two numbers: (i) the change in output when the factor goes from low to high level as the other factor stays low and (ii) the change in output when the factor goes from low to high level as the other factor stays high.

It must be illustrated that apart from 'main effects', factors can like-wise result in interaction effects. Interaction effects

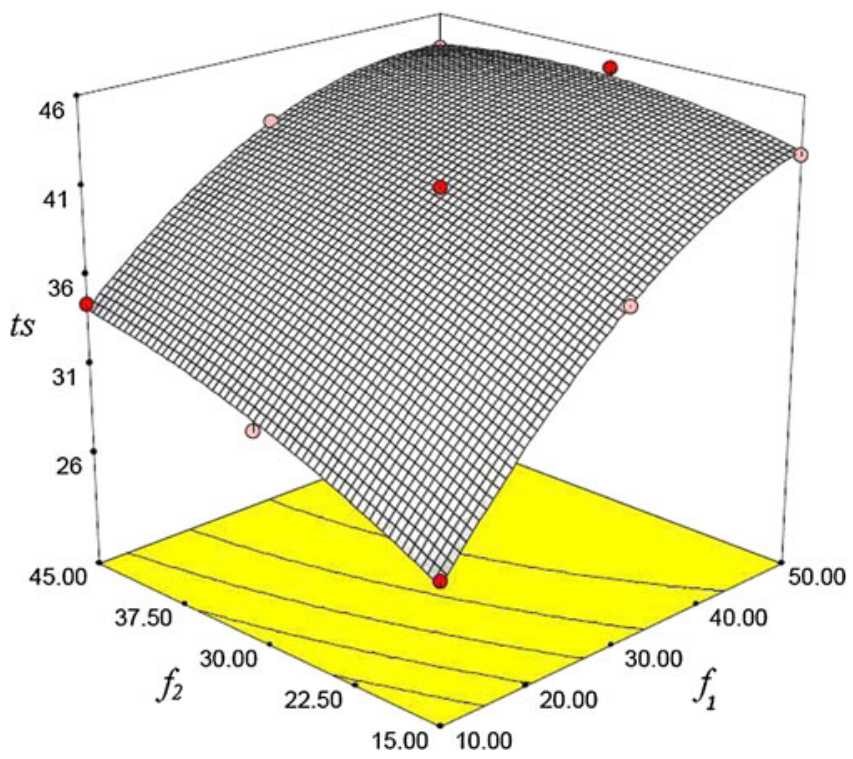

Figure 4. Optimum fibre parameter values obtained from factorial design method for $t s$. 
are changes in the process output caused by two or more factors that are interacting with each other. Large interactive effects can make the main effects insignificant, such that it becomes more important for the engineer to pay attention to the interaction of the involved factors than to investigate them individually.

The running of factorial combinations and the mathematical interpretation of the output responses of the process to such combinations is the essence of factorial experiments. It allows an engineer to understand which factors affect the

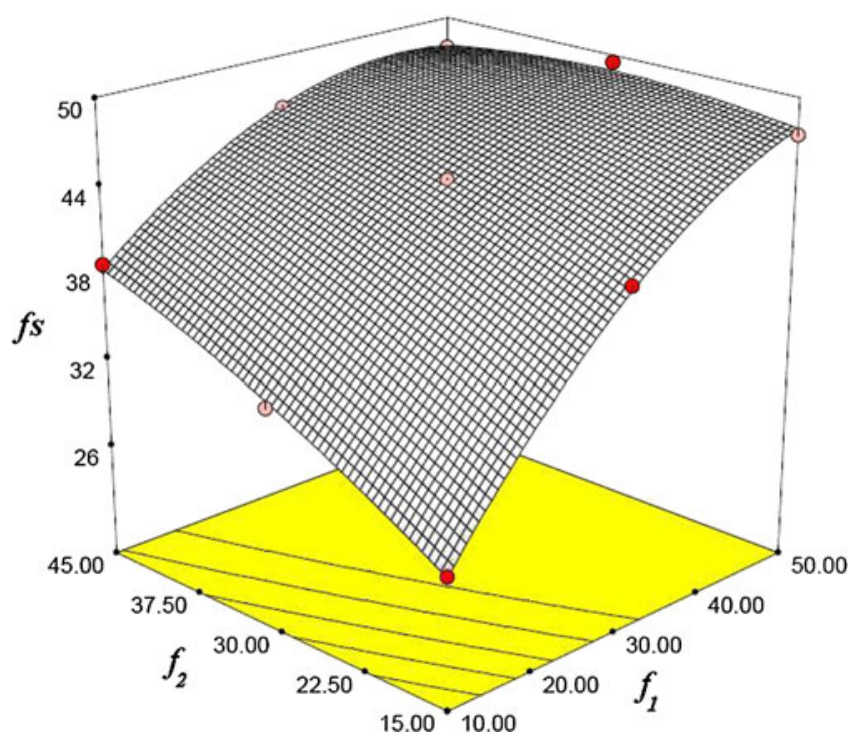

Figure 5. Optimum fibre parameter values obtained from factorial design method for $f s$.

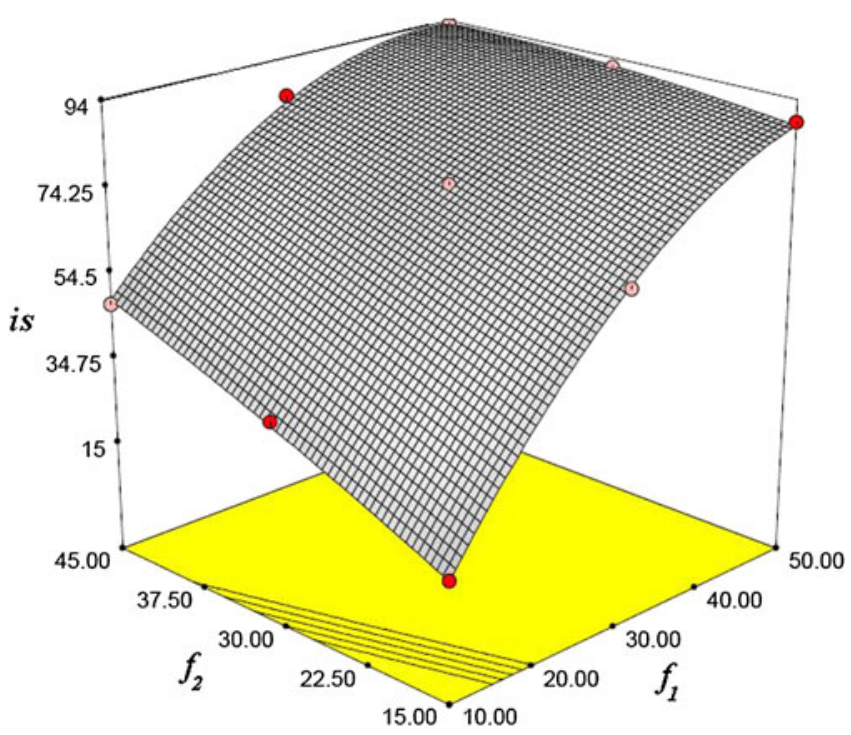

Figure 6. Optimum fibre parameter values obtained from factorial design method for $i s$. process most, so that improvements (or corrective actions) may be attained (figures 4-6).

\section{Non-linear regression analysis}

The mechanical properties such as tensile, flexural and impact strength were modeled using second-order polynomial curve fitting equations using Design Expert statistical software (Jayabal and Natarajan 2011). Equations (1)(3) are the developed nonlinear regression models of tensile strength $(t s)$, flexural strength $(f s)$ and impact strength $(i s)$, respectively.

$$
\begin{aligned}
t s= & 11 \cdot 622+0.909 f_{1}+0.575 f_{2}-0.005 f_{1} \\
& \times f_{2}-0.007 f_{1}^{2}-0.004 f_{2}^{2}, \\
f s= & 7 \cdot 16+1.179 f_{1}+0.74 f_{2}-0.009 f_{1} \\
& \times f_{2}-0.008 f_{1}^{2}-0.004 f_{2}^{2}, \\
i s= & -41.82+4.05 f_{1}+1.68 f_{2}-0.023 f_{1} \\
& \times f_{2}-0.031 f_{1}^{2}-0.006 f_{2}^{2} .
\end{aligned}
$$

\section{Analysis of variance}

ANOVA technique can be used to investigate any number of factors which are hypothesized or said to influence the dependent variable. This design consisted of two factors, each at three levels.

\subsection{ANOVA for tensile strength test}

The list of degrees of freedom, sum of squares and mean square for tensile strength model are given in table 2. The fit was exact and $R^{2}$ value is 0.9974 . The model $F$-value of 229.266 implies that the model is significant. There is only $0.05 \%$ chance that a "model $F$-value" of this large value could occur due to noise. Values of "probability $>F$ " less than $0 \cdot 0500$ indicate that the model terms are significant. In this case, $f_{1}, f_{2}, f_{1} \times f_{2}, f_{1}^{2}$ are significant model terms. Values greater than $0 \cdot 1000$ indicate that the model terms are not significant. So, $f_{2}^{2}$ is not significant.

\subsection{ANOVA for flexural strength test}

The list of degrees of freedom, sum of squares and mean square for flexural strength model are given in table 3 . The fit was exact and $R^{2}$ value is 0.998 . The model $F$-value of 257.779 implies that the model is significant. There is only $0.04 \%$ chance that a "model $F$-value" of this largeness could occur due to noise. Values of "probability $>F$ " less than 0.0500 indicate that the model terms are significant. In this case, $f_{1}, f_{2}, f_{1} \times f_{2}, f_{1}^{2}$ are significant model terms. Values 
Table 2. ANOVA for tensile strength model.

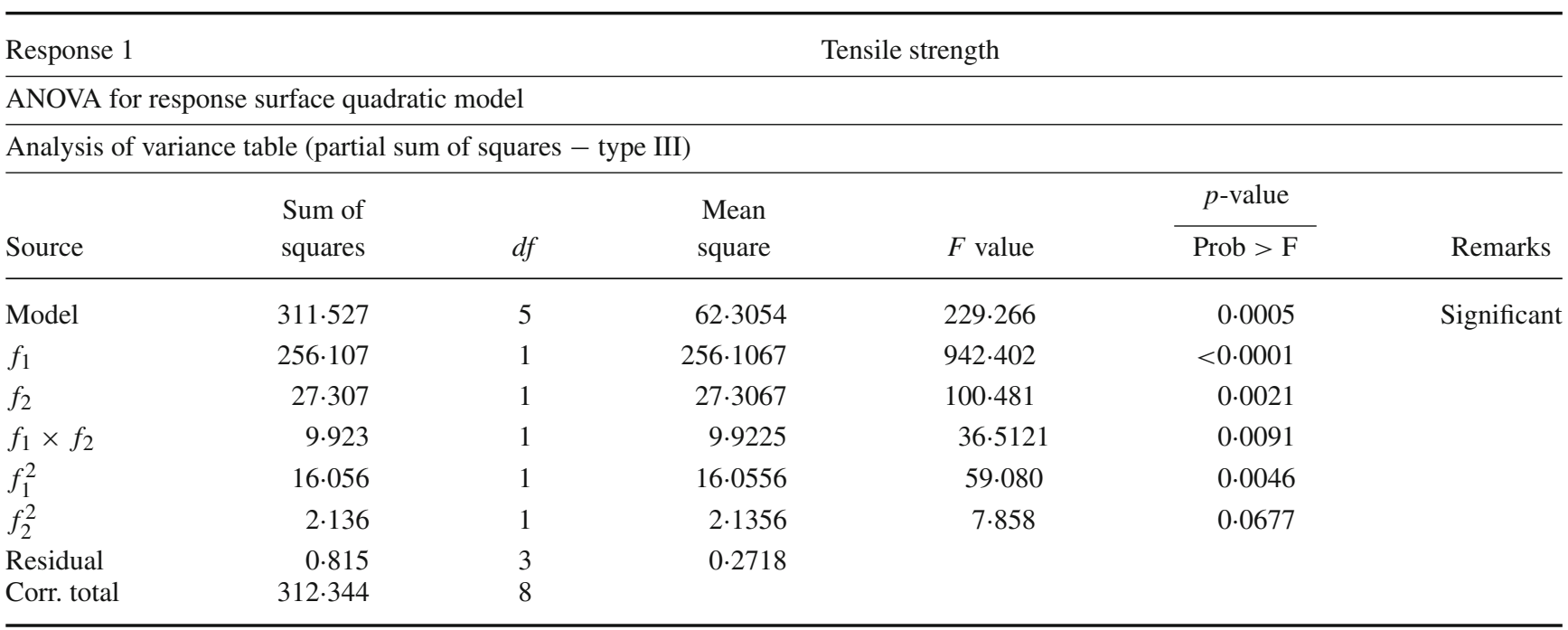

Table 3. ANOVA for flexural strength model.

\begin{tabular}{|c|c|c|c|c|c|c|}
\hline \multicolumn{3}{|l|}{ Response 2} & \multicolumn{2}{|c|}{ Flexural strength } & & \\
\hline \multicolumn{7}{|c|}{ ANOVA for response surface quadratic model } \\
\hline \multicolumn{7}{|c|}{ Analysis of variance table (partial sum of squares - type III) } \\
\hline Source & $\begin{array}{l}\text { Sum of } \\
\text { squares }\end{array}$ & $d f$ & $\begin{array}{l}\text { Mean } \\
\text { square }\end{array}$ & $F$ value & $\begin{array}{c}p \text {-value } \\
\text { Prob > F }\end{array}$ & Remarks \\
\hline Model & 461.974 & 5 & 92.395 & 257.779 & $0 \cdot 0004$ & Significant \\
\hline$f_{1}$ & $354 \cdot 202$ & 1 & $354 \cdot 202$ & $988 \cdot 214$ & $<0 \cdot 0001$ & \\
\hline$f_{2}$ & $49 \cdot 882$ & 1 & $49 \cdot 882$ & $139 \cdot 168$ & 0.0013 & \\
\hline$f_{1} \times f_{2}$ & 33.063 & 1 & 33.063 & $92 \cdot 244$ & 0.0024 & \\
\hline$f_{1}^{2}$ & $22 \cdot 894$ & 1 & $22 \cdot 893$ & $63 \cdot 873$ & $0 \cdot 0041$ & \\
\hline$f_{2}^{2}$ & 1.934 & 1 & 1.934 & $5 \cdot 395$ & $0 \cdot 1028$ & \\
\hline Residual & $1 \cdot 075$ & 3 & $0 \cdot 358$ & & & \\
\hline Corr. total & $463 \cdot 05$ & 8 & & & & \\
\hline
\end{tabular}

Table 4. ANOVA for impact strength model.

\begin{tabular}{|c|c|c|c|c|c|c|}
\hline \multicolumn{3}{|l|}{ Response 3} & \multicolumn{2}{|c|}{ Impact strength } & & \\
\hline \multicolumn{7}{|c|}{ ANOVA for response surface quadratic model } \\
\hline \multicolumn{7}{|c|}{ Analysis of variance table (partial sum of squares - type III) } \\
\hline \multirow[b]{2}{*}{ Source } & \multirow{2}{*}{$\begin{array}{l}\text { Sum of } \\
\text { squares }\end{array}$} & & \multirow{2}{*}{$\begin{array}{l}\text { Mean } \\
\text { square }\end{array}$} & \multirow[b]{2}{*}{$F$ value } & $p$-value & \multirow[b]{2}{*}{ Remarks } \\
\hline & & $d f$ & & & Prob $>$ F & \\
\hline Model & $6180 \cdot 040$ & 5 & $1236 \cdot 008$ & $619 \cdot 179$ & $0 \cdot 0001$ & Significant \\
\hline$f_{1}$ & $5133 \cdot 375$ & 1 & $5133 \cdot 375$ & $2571 \cdot 576$ & $<0 \cdot 0001$ & \\
\hline$f_{2}$ & $532 \cdot 042$ & 1 & $532 \cdot 042$ & $266 \cdot 527$ & $0 \cdot 0005$ & \\
\hline$f_{1} \times f_{2}$ & $189 \cdot 063$ & 1 & $189 \cdot 063$ & $94 \cdot 711$ & 0.0023 & \\
\hline$f_{1}^{2}$ & $321 \cdot 734$ & 1 & $321 \cdot 734$ & $161 \cdot 172$ & $0 \cdot 0011$ & \\
\hline$f_{2}^{2}$ & $3 \cdot 827$ & 1 & $3 \cdot 827$ & $1 \cdot 9173$ & $0 \cdot 2602$ & \\
\hline Residual & $5 \cdot 989$ & 3 & 1.996 & & & \\
\hline Corr. total & $6186 \cdot 03$ & 8 & & & & \\
\hline
\end{tabular}


$>0 \cdot 1000$ indicate that the model terms are not significant. Hence, $f_{2}^{2}$ is not significant.

\subsection{ANOVA for impact strength test}

The list of degrees of freedom, sum of squares and mean square for impact strength model are given in table 4 . The fit was exact and $R^{2}$ value is 0.998 . The model $F$-value of 619.179 implies that the model is significant. There is only $0.01 \%$ chance that "model $F$-value" of this largeness could occur due to noise. Values of "probability $>F$ " less than 0.0500 indicate that the model terms are significant. In this case, $f_{1}, f_{2}, f_{1} \times f_{2}, f_{1}^{2}$ are significant model terms. Values $>0.1000$ indicate that the model terms are not significant. So, $f_{2}^{2}$ is not significant.

\section{Genetic algorithm technique}

GAs were introduced by Prof John Holland (1975) of the University of Michigan. Genetic algorithms are computerized search and optimization algorithms based on the mechanics of natural selection (Rajasekaran and Vijayalakshmi Pai 2005) and it can search the entire search space to find the global optimum. Therefore, this technique has been used as a powerful tool for optimizing functions with numerous applications. It requires only an objective function to guide their search.

Genetic algorithms require design space to be converted into genetic space. So, genetic algorithms work with a coding of variables. The data processed by GA consisted of a set of strings (or chromosomes) with a finite length in which each bit is called an allele (or a gene).

A selected number of strings are called as population and the population at a given time is a generation. Generation of the initial population of strings is done randomly. New chromosomes can be generated using genetic operators. The genetic operators operate on the genes to replace their place within the chromosome. Since, the binary alphabet proposes the maximum number of schemata per bit of information of any coding (Goldberg 1989), a binary encoding scheme is traditionally used to represent the chromosomes using either zeros or ones. Other encodings such as octal encoding, hexadecimal encoding, permutation encoding, value encoding and tree encoding are also possible.

Reproduction is the first operator applied on population. Chromosomes are selected from the population to be parents to crossover and produce offspring. The best one should survive and create new offspring according to Darwin's evolution theory of survival of the fittest.
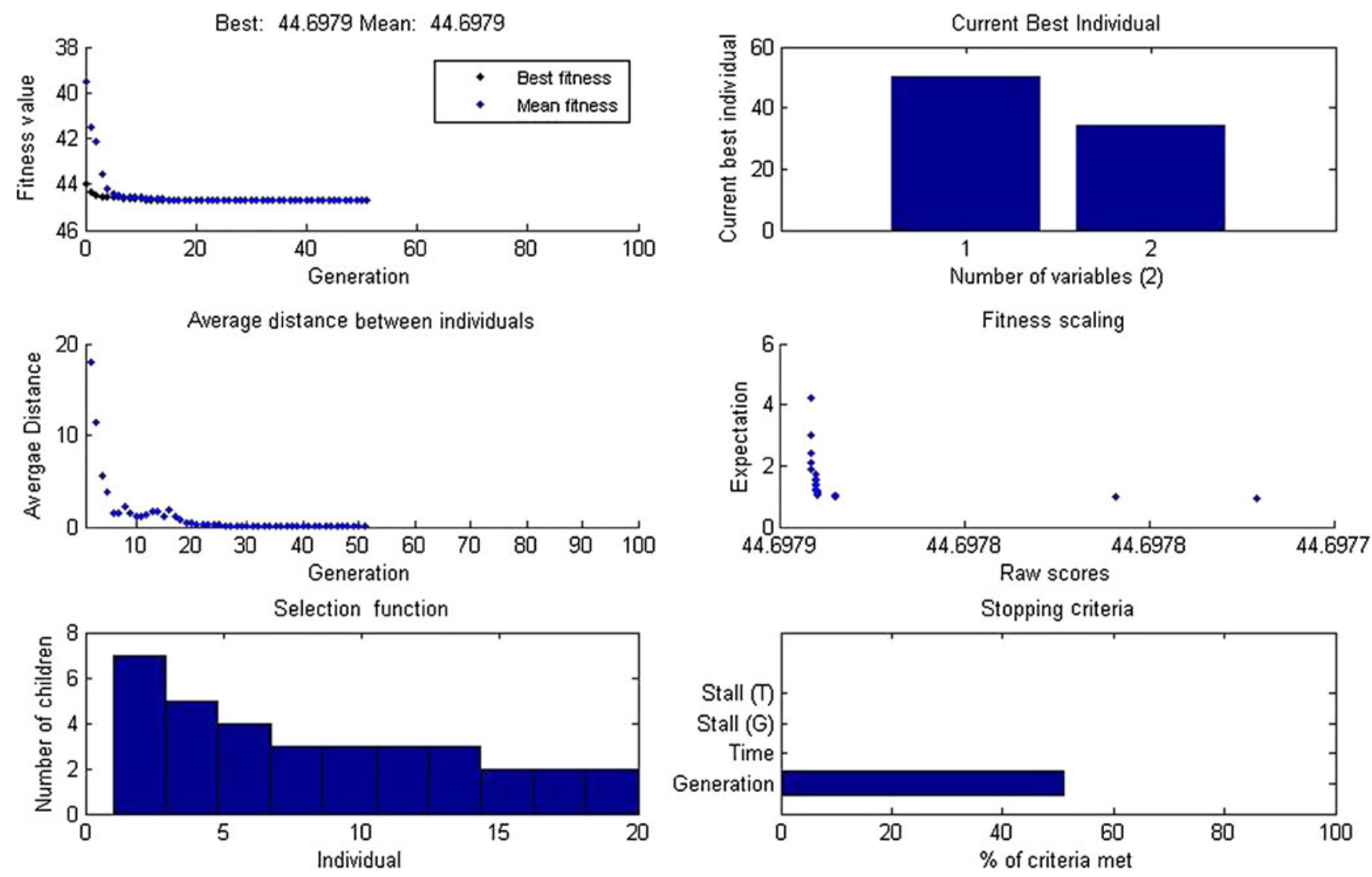

Figure 7. Optimum fibre parameter values obtained from GA method for tensile strength. 

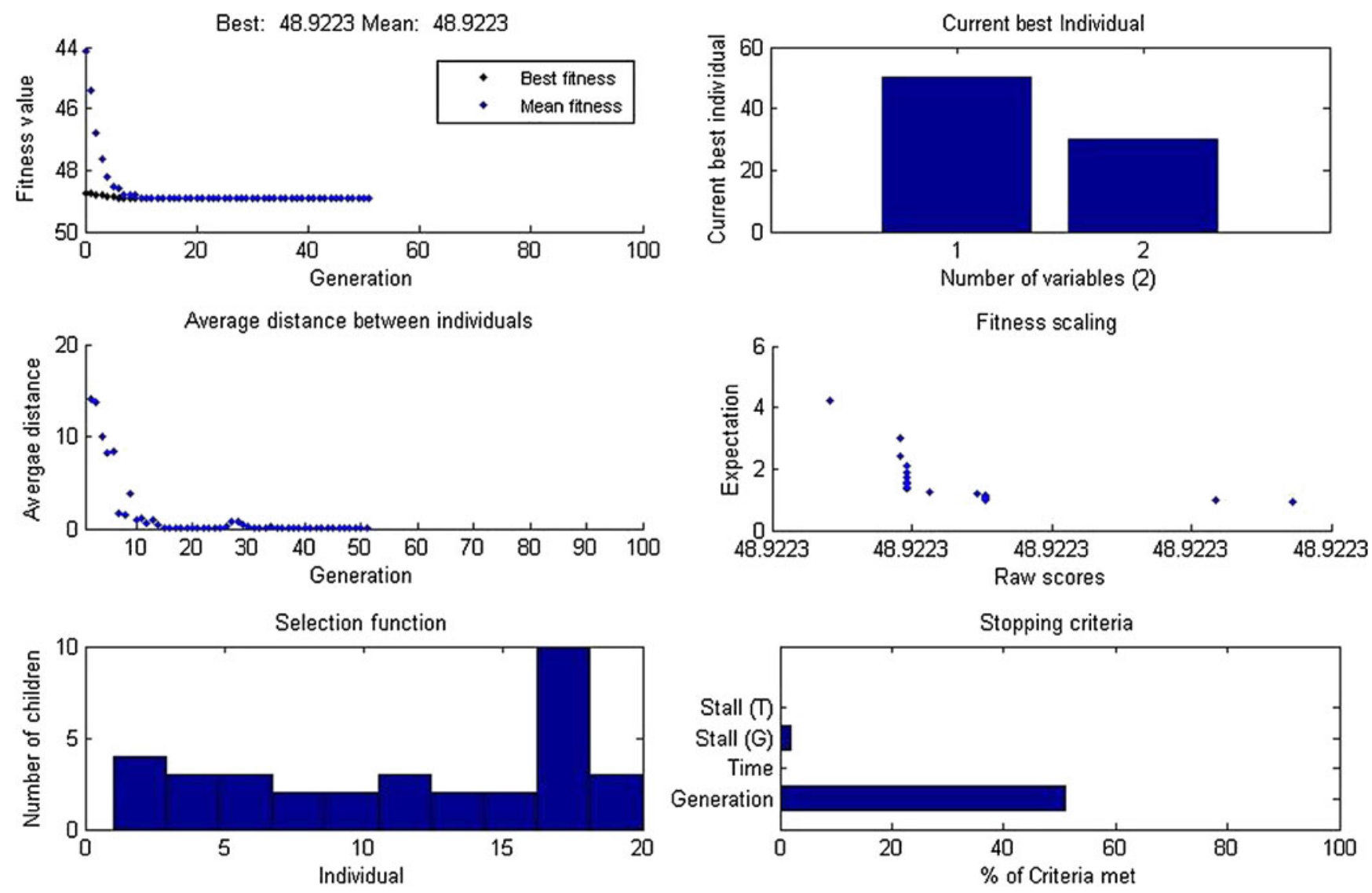

Figure 8. Optimum fibre parameter values obtained from GA method for flexural strength.

In Roulette wheel selection, each member of the pool is assigned space on a Roulette wheel proportional to its fitness. The members with the greatest fitness have the highest probability of selection. This selection technique works only for GA which maximizes its objective function.

Crossover, inversion and mutation are the three main genetic operators used for global searches, although there are other types of genetic operators that can yield good results. In the crossover operator, new strings are created by exchanging information among strings of the mating pool.

Simple crossover involves two parents and crossover points are selected randomly. If two parents to be used for generating new chromosomes are $\left\{\right.$ Parent A: $\left.\begin{array}{llllllll}0 & 0 & 1 & 0\end{array}\right\}$ and \{Parent B: $\left.\begin{array}{lllllll}0 & 1 & 1 & 0\end{array}\right\}$ and a crossover point was chosen randomly as 2; this produces the following children: \{Child A: $10 \mid \begin{array}{lll}1 & 1 & 0\end{array}$ and $\left\{\right.$ Child B: $10|0| \begin{array}{lll}0 & 0\end{array}$.

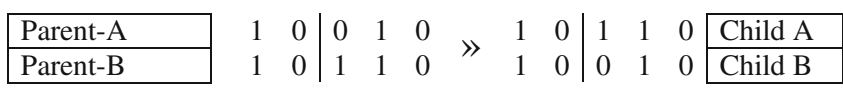

Inversion: A string from the population is selected and the bits between two random sites are inverted as shown below:

\begin{tabular}{|c|c|c|c|c|c|c|}
\hline 1 & 0 & $\mathbf{1}$ & 1 & $\mathbf{0}$ & $\mathbf{0}$ & 1 \\
\hline 1 & 0 & 0 & 0 & 1 & 1 & 1 \\
\hline & & \multicolumn{4}{|c|}{$\begin{array}{l}\text { Bits between } \\
\text { sites inverted }\end{array}$} & \\
\hline
\end{tabular}

Mutation of a bit involves flipping it, i.e. changing $0-1$ and vice versa with mutation probability. The mutation operator searches in the entire space in the given time. Restores lost information or adds information to the population. Mutation operation was performed on a child after crossover function. Performed infrequently (for example, 0.005 probability of altering a gene in a chromosome).

$\begin{array}{llllllllllllll}\text { Child-1 } & 1 & 1 & 0 & 1 & 0 & 0 & 0 & 0 & 1 & 0 & 0 & 1 & 1\end{array}$

After mutation $1 \begin{array}{lllllllllllll}1 & 1 & 0 & 1 & \mathbf{1} & 0 & 0 & 0 & 1 & 0 & 0 & 1 & 1\end{array}$

In the Matlab software, the following options have been selected: population: double vector, population size: 20 , fitness scaling: rank, selection: stochastic uniform, reproduction: elite count-2, mutation function: constraint dependent, cross over: scattered and migration: forward direction.

Stopping criteria: Generations: 100, time limit: infinitive, fitness limit: infinitive, stall generation: 50, stall time limit: infinitive, function tolerance: 1e-6 and nonlinear constraint tolerance: $1 \mathrm{e}-6$.

Results are plotted in figures 7-9 for tensile, flexural and impact strengths, respectively.

\section{Optimization of parameters}

Optimization of responses includes the work of finding the optimum set of experimental factors that will produce 

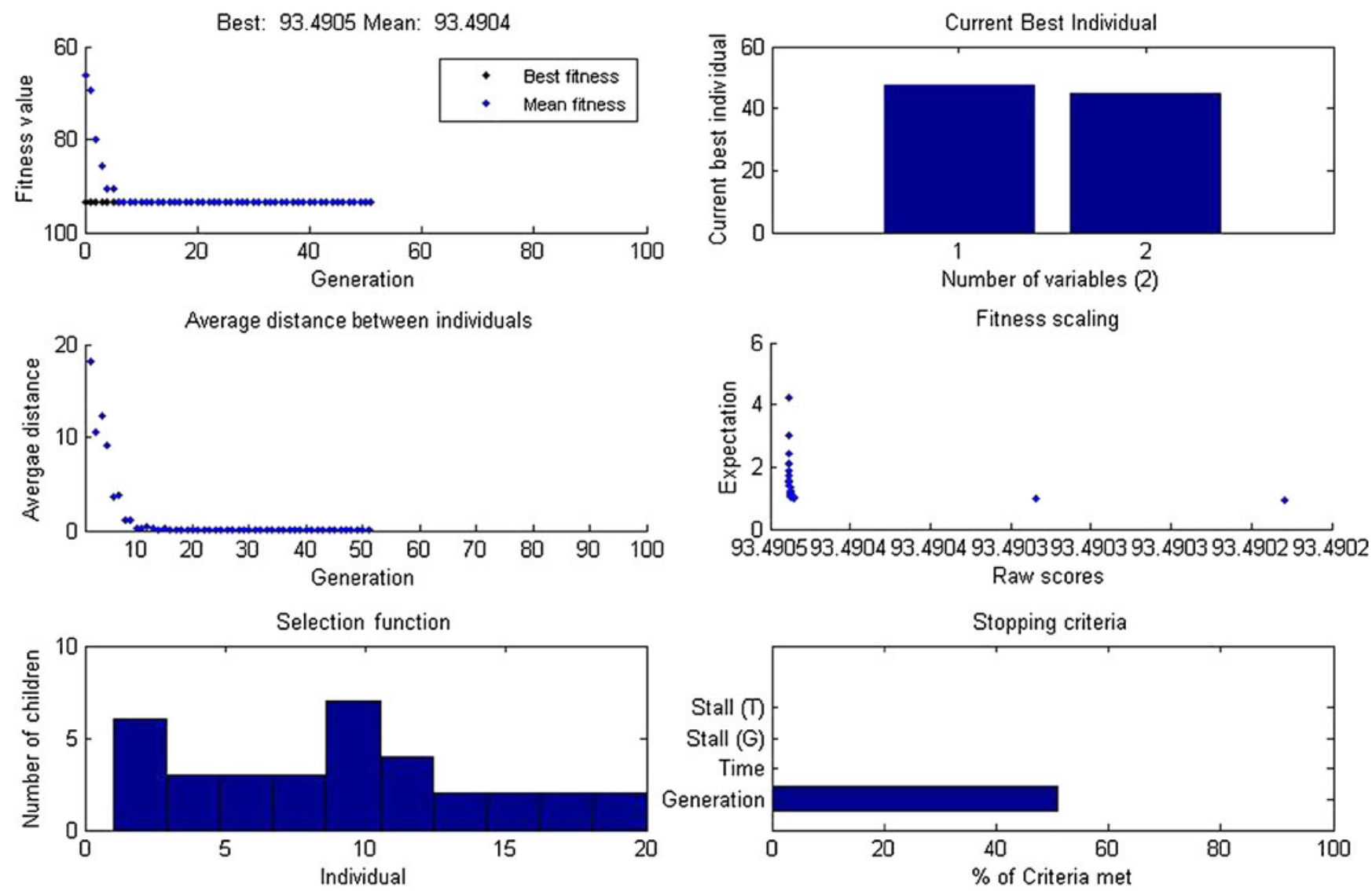

Figure 9. Optimum fibre parameter values obtained from GA method for impact strength.

Table 5. Optimal fibre parameters obtained from factorial design and GA.

\begin{tabular}{|c|c|c|c|c|c|c|c|c|c|}
\hline \multicolumn{2}{|c|}{ Fibre length $(\mathrm{mm})$} & \multicolumn{2}{|c|}{ Fibre content (wt $\%$ ) } & \multicolumn{2}{|c|}{ Tensile strength (MPa) } & \multicolumn{2}{|c|}{ Flexural strength (MPa) } & \multicolumn{2}{|c|}{ Impact strength $(\mathrm{J} / \mathrm{m})$} \\
\hline $\begin{array}{l}\text { Factorial } \\
\text { design }\end{array}$ & GA & $\begin{array}{c}\text { Factorial } \\
\text { design }\end{array}$ & GA & $\begin{array}{c}\text { Factorial } \\
\text { design }\end{array}$ & GA & $\begin{array}{c}\text { Factorial } \\
\text { design }\end{array}$ & GA & $\begin{array}{c}\text { Factorial } \\
\text { design }\end{array}$ & GA \\
\hline 50 & 50 & $34 \cdot 05$ & $34 \cdot 048$ & 44.697 & 44.698 & - & - & - & - \\
\hline 50 & 50 & $33 \cdot 78$ & $30 \cdot 07$ & - & - & $48 \cdot 86$ & $48 \cdot 922$ & - & - \\
\hline 50 & $47 \cdot 641$ & $35 \cdot 33$ & 45 & - & - & - & - & $92 \cdot 88$ & 93.491 \\
\hline 50 & 50 & $33 \cdot 94$ & 34 & 44.697 & $44 \cdot 701$ & $48 \cdot 856$ & $48 \cdot 87$ & - & - \\
\hline 50 & 50 & $34 \cdot 05$ & $34 \cdot 071$ & - & - & $48 \cdot 852$ & $48 \cdot 853$ & $92 \cdot 74$ & $92 \cdot 741$ \\
\hline 50 & 50 & $34 \cdot 17$ & $34 \cdot 172$ & 44.697 & 44.699 & - & - & 92.74 & $92 \cdot 75$ \\
\hline 50 & 50 & $34 \cdot 05$ & $34 \cdot 051$ & 44.6976 & 44.697 & $48 \cdot 852$ & $48 \cdot 852$ & $92 \cdot 7406$ & 93.491 \\
\hline
\end{tabular}

maximum value of responses. In this study, optimal parameters were found using factorial design technique and GA method through the Design Expert and Matlab software. The best possible combination of input parameters for maximum value of tensile, flexural and impact strengths are shown in table 5. The optimization module in the software package searches for various combinations of input parameters and satisfies the objective function as well as maintains the limit of factor values within the limit. For in between values of factors, the responses can be predicted using point prediction mode of the software.

\section{Results and discussion}

Sisal-vinyl ester composite shows the average values for tensile, flexural and impact strengths of $44.698 \mathrm{MPa}$, 48.852 $\mathrm{MPa}$ and $92.74 \mathrm{~J} / \mathrm{m}$, respectively. In this work, mechanical properties of two main factors $f_{1}$ and $f_{2}$ and interaction effects of $f_{1} \times f_{2}$ and $f_{1}^{2} \times f_{2}^{2}$ were studied. All the terms were included in the regression model of secondorder response for getting minimum standard error. From ANOVA result, the following suggestions were made: (i) in the tensile strength analysis, the most significant variable 
Table 6. Validation of mathematical model.

\begin{tabular}{|c|c|c|c|c|c|c|c|c|c|c|}
\hline \multirow[b]{2}{*}{$f_{1}(\mathrm{~mm})$} & \multirow[b]{2}{*}{$f_{2}(\mathrm{wt} \%)$} & \multicolumn{3}{|c|}{ Experimental values } & \multicolumn{3}{|c|}{ Predicted values } & \multicolumn{3}{|c|}{$\%$ of error } \\
\hline & & ts $(\mathrm{Mpa})$ & $f s(\mathrm{Mpa})$ & is $(\mathrm{J} / \mathrm{m})$ & ts (Mpa) & $f s(\mathrm{Mpa})$ & is $(\mathrm{J} / \mathrm{m})$ & ts (Mpa) & $f_{s}(\mathrm{Mpa})$ & is $(\mathrm{J} / \mathrm{m})$ \\
\hline 25 & 40 & 38 & 44 & 72 & $40 \cdot 3373$ & $44 \cdot 4543$ & $74 \cdot 2925$ & $6 \cdot 151$ & $1 \cdot 033$ & $3 \cdot 184$ \\
\hline 30 & 35 & $40 \cdot 5$ & $44 \cdot 2$ & 79 & $41 \cdot 5185$ & $45 \cdot 4741$ & $78 \cdot 5741$ & $2 \cdot 515$ & $2 \cdot 883$ & 0.539 \\
\hline 35 & 30 & $40 \cdot 8$ & 44 & 80 & $42 \cdot 3785$ & $46 \cdot 33$ & $82 \cdot 1087$ & $3 \cdot 869$ & $5 \cdot 295$ & $2 \cdot 636$ \\
\hline 40 & 25 & 43 & 46 & 85 & $42 \cdot 9171$ & $47 \cdot 0269$ & 84.8963 & $0 \cdot 193$ & $2 \cdot 232$ & $0 \cdot 122$ \\
\hline 50 & 15 & $42 \cdot 5$ & 48 & 86 & 43.0306 & $47 \cdot 9306$ & $88 \cdot 2306$ & $1 \cdot 248$ & $0 \cdot 145$ & $2 \cdot 594$ \\
\hline \multicolumn{5}{|c|}{ Average absolute error } & & & & $2 \cdot 795$ & $2 \cdot 318$ & $1 \cdot 815$ \\
\hline
\end{tabular}

was $f_{1}$. The interaction between $f_{1}$ and $f_{1}$ contributed maximum. The interactions between the following variables were less significant; $f_{2} \times f_{2}$ and $f_{1} \times f_{2}$, (ii) in the flexural strength analysis, the most significant variable was $f_{1}$. The interaction between $f_{1} \times f_{2}$ contributed maximum. The interactions between the following variables were less significant; $f_{1} \times f_{1}$ and $f_{2} \times f_{2}$, (iii) in the impact strength analysis, the most significant variable was fibre length. The interaction between $f_{1} \times f_{1}$ was maximum. The interactions between the following variables were less significant; $f_{2} \times f_{2}$ and $f_{1} \times f_{2}$, (iv) this paper reports the optimization of fibre parameters in table 5 in order to achieve the optimal responses. The optimal values were obtained from factorial design and GA are noted in table 5, (v) the optimum parameter settings are $f_{1}=50 \mathrm{~mm}, f_{2}=34.05 \%$ and in these settings, all responses are gaining maximum values, $t s=44.698(\mathrm{MPa}), f s=48.852(\mathrm{MPa})$ and $i s=92.74$ $(\mathrm{J} / \mathrm{m})$ and (vi) confirmation experiments were conducted for five sets of conditions. The experimental values and the predicted values obtained from regression model were compared. The percentage of error was calculated using the following formula for the validation of regression model (table 6):

$$
\begin{aligned}
\% \text { of error }= & (\text { experimental value }- \text { predicted value }) \\
& / \text { experimental value } \times 100 .
\end{aligned}
$$

From table 6 , the average absolute error for tensile strength $=2.795 \%$, flexural strength $=2.318 \%$ and impact strength $=1.815 \%$ was observed and better accuracy was obtained using the developed regression models.

\section{Conclusions}

The following conclusions were drawn:

(I) The fibre length plays a prominent role in deciding the mechanical properties of sisal composite compared with fibre content.

(II) In the interactions between fibre length and fiber content, fibre length in second-order polynomial is more significant than fibre content in the tensile and impact tests.
(III) From the result of optimization, the best combination of fibre parameters $\left(f_{1}=50 \mathrm{~mm}\right.$ and $f_{2}=34.05(\mathrm{wt} \%)$ are determined to attain maximum value of tensile, flexural and impact strengths.

(IV) From the results obtained (table 5), genetic algorithm proved as an efficient technique than factorial design method in achieving the objective function.

\section{Acknowledgements}

The authors acknowledge the support of Mr G Tharanidharan and S Gnanakumar, Department of Mechanical Engineering, Kongu Engineering College, Erode, to carry out mechanical testing.

\section{References}

Cruz-Ramos and Carlos A 1986 Mechanical properties of reinforced thermoplastics (Springer) p. 65

Goldberg D E 1989 Genetic algorithms in search, optimization, and machine learning (Addison-Wesley)

Jayabal S and Natarajan U 2011 Int. J. Adv. Manuf. Technol. 54639

Jayabal S, Natarajan U and Sekar U 2011 Int. J. Adv. Manuf. Technol. 55263

Joly C, Gauthier R and Escouben M 1996 J. Appl. Polym. Sci. 6157

Joseph P V, Kuruvilla Joseph and Sabu Thomas 1999 Compos. Sci. Technol. 591625

Noorunnisa Khanam P, Abdul Khalil H P S, Jawaid M, Ramachandra Reddy G, Surya Narayana C and Venkata Naidu S 2010 J. Polym. Environ. 18727

Pavithran C, Mukherjee P S, Brahmakumar M and Damodaran A D 1987 J. Mater. Sci. Lett. 6882

Rajasekaran S and Vijayalakshmi Pai G A 2005 Neural networks, fuzzy logic and genetic algorithms (New Delhi: Prentice-Hall of India) p. 228

Sotton M and Ferrari M 1989 L'industrie Textile 119758

Woodhams R T, Thomas G and Rodgers D K 1984 Polym. Eng. Sci. 241166

Yadav Ranjana, Devi Archana, Tripathi Garima and Srivastava Deepak 2007 Euro. Polym. J. 433531

Zhang S and Horrocks A R 2003 Prog. Polym. Sci. 281517

Zhong J B, Lv J and Wei C 2007 Express Polym. Lett. 10681 